\title{
The New Method Developed for Evaluation of Anthelmintic Activity by Housefly Worms and Compared with Conventional Earthworm Method
}

\author{
V. Murugamani, ${ }^{1}$ L. Raju, ${ }^{2}$ V. Baskar Anand Raj, ${ }^{3}$ Manjir Sarma kataki, ${ }^{1}$ and G. Girija Sankar ${ }^{3}$ \\ ${ }^{1}$ Department of Pharmaceutical Biotechnology, Abhilashi College of Pharmacy, Tanda, Ner-Chowk, Mandi-175008, \\ Himachal Pradesh, India \\ ${ }^{2}$ School of Pharmacy and Engineering \& Technology, Chail-Chowk, Mandi, Himachal Pradesh, India \\ ${ }^{3}$ Department of Pharmaceutical Biotechnology, Andhra University College of Pharmacy, Andhra University, Vishakapattanam, \\ Andhra Pradesh, India
}

Correspondence should be addressed to V. Murugamani, vmurugamani@rediffmail.com

Received 27 November 2011; Accepted 11 January 2012

Academic Editors: M. Alkondon and D. K. Miller

Copyright (c) 2012 V. Murugamani et al. This is an open access article distributed under the Creative Commons Attribution License, which permits unrestricted use, distribution, and reproduction in any medium, provided the original work is properly cited.

\begin{abstract}
Evaluation of anthelmintic activity of any drug when carried out in laboratory conditions by using the isolated worms from nature cannot be adaptable with artificial laboratory conditions. Therefore, the present study aims at developing a new adaptable method for evaluation of anthelmintic activity. The present anthelmintic activity study reveals a new methodology with housefly worms cultured in laboratory conditions that resemble parasitic pinworms found in human being. We studied the anthelmintic activities of various drugs on housefly worms and earthworms. The results showed that the housefly worms had taken more time for paralysis and death. Even after paralysis the time taken for death is more in housefly worms in spite of smaller size and lesser weight of the worms compared to earthworms. The study concluded that the earthworms have not adapted to the artificial laboratory conditions leading to erratic results. Therefore, culturing of housefly worms was carried out to evaluate the anthelmintic activity and found an easy, prominent, eco-friendly, and reproducible method in all aspects such as equal age, size, and weight of worms used for the experiment.
\end{abstract}

\section{Introduction}

Helminthes infections are among the most common infections in human beings in which human intestinal parasitic worms are vectored through air, food, and water, which causes disease state, secretes toxins, and steals the vital nutrients from host bodies [1]. Present treatment regimens for these diseases have limitations as the currently used anthelmintic drugs are mainly microfilaricidal, with little effect on the adult worms; hence new drugs are urgently required. In this regard, natural products have made and continue to make important contributions to this therapeutic area. The drugs currently used for helminthes infections include combinations of DEC (diethylcarbamazine) and albendazole, ivermectin and albendazole or the use of DEC fortified salt, which has also been described in [2]. Previous studies have also reported that none of these is effective in killing the adult worms, which can live in the host for several years [3]. This emphasizes the need for developing an effective and safe drug to kill or permanently sterilize the adult worms. One of the methods for identifying leads for drug development is to screen drugs for the required activity, which has been reported in $[4,5]$ (Figure 1).

Evaluations of anthelmintic activity of any drug when carried out in artificial laboratory conditions by using the earthworms (Lumbricus terrestris), isolated intestinal worms (from animals) and isolated Ascaris lumbricoides from stools (human) cannot be adaptable with artificial laboratory conditions, as reported previously [6]. Earthworms are also called megadriles or big worms, as opposed to the microdriles or small worms in the families Tubificidae, Lumbriculidae, and Enchytraeidae, among others. The earthworms 


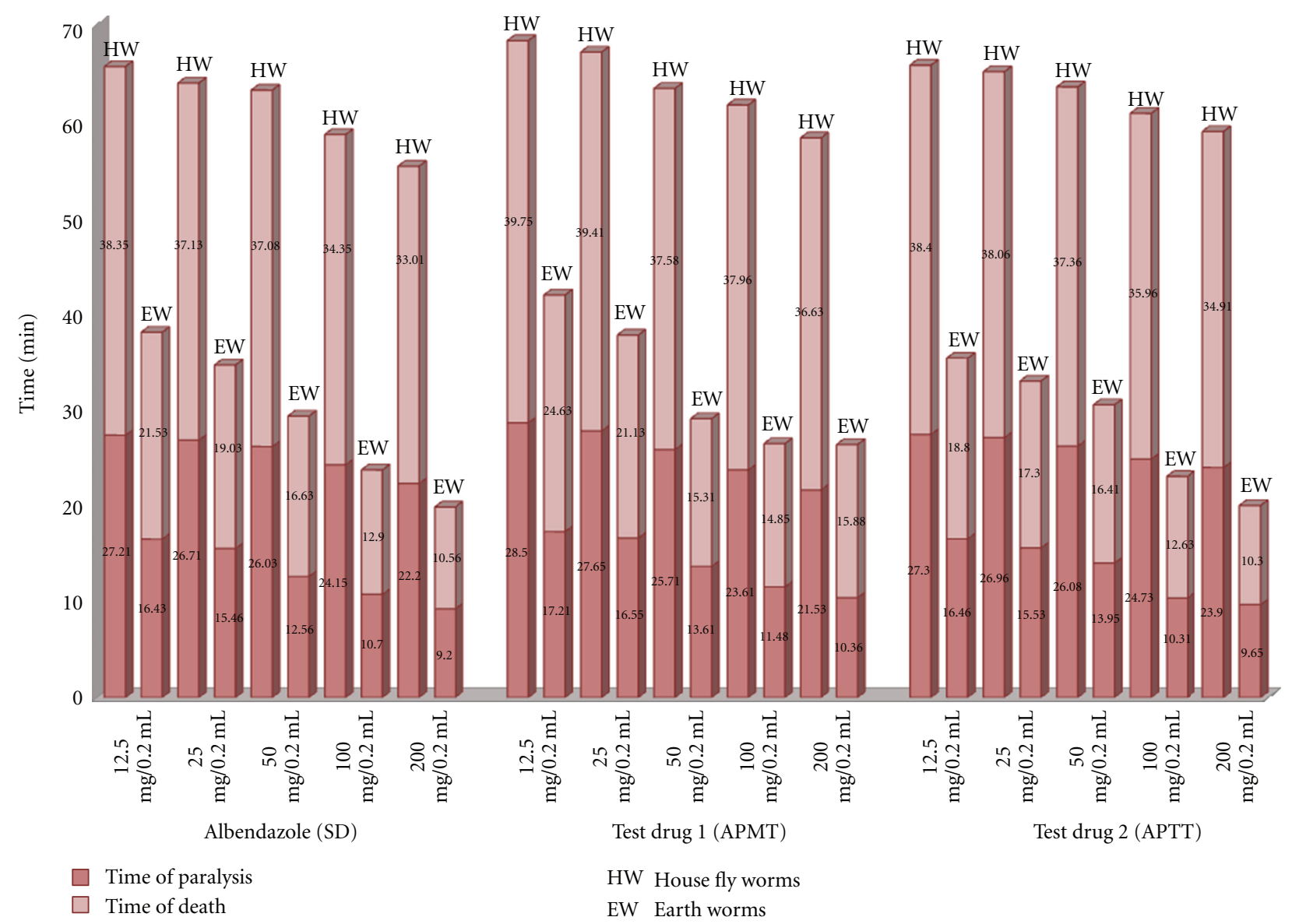

FIgURE 1: Comparative studies of the anthelmintic activities of albendazole and test durgs 1 and 2 in housefly worms and earthworms.

are eco-friendly for decomposing organic materials, feeding upon undecayed leaves and other plant materials, more geophagous $[7,8]$.

So the objective of the present anthelmintic activity study reveals a new methodology with housefly worms in laboratory conditions that resemble pinworms in human infections. The method developed shows easy analysis with worms equal in age, size, weight, and adaptable environment, which has been taken to evaluate the anthelmintic activity with housefly worms. The method so developed in the present study was found to be easy, economic, reliable, reproducible, and simple compared with the conventional method as well as being eco-friendly.

\section{Materials and Methods}

2.1. Collection of Houseflies. Houseflies (Stomoxys calcitrans) were collected in perforated sterile plastic jar from the canteen of Abhilashi College of Pharmacy, Tanda, Mandi, HP and authenticated by Dr. Humanan Reddy, Professor of Entomology, Department of Zoology, Vikrama Simhapuri University, Nellore, TN.

2.1.1. Housefly Worm Medium Preparation. The housefly worm medium was prepared by adding beef extract powder
(1.2 gm) (Hi-media, India) with nutrient agar (Hi-media, India) medium. Nutrient agar was used to enhance the nutrients for the housefly. The medium was adjusted to pH 7.2 and sterilized in autoclave (Lab Chem. Model DD 745 , India) at $121^{\circ} \mathrm{C}$ for 15 minutes. Amoxicillin $100 \mu \mathrm{g} / \mathrm{mL}$ and clotrimazole $75 \mu \mathrm{g} / \mathrm{mL}$ were also added to the medium to prevent the growth of other microorganisms. After sterilization $20 \mathrm{~mL}$ media were poured into 10 Petri dishes and kept for solidification. The matured female houseflies were placed in each of the Petri dishes, which were then closed and kept at room temperature. Upon appearance of the housefly worms, 20 worms were collected by a small surgical forceps and weighed in a Shimadzu high precision balance. Afterwards average weight of a single worm was calculated and found as $0.01 \mathrm{mg}$.

2.2. Preparation of Drug Solutions. The standard drug albendazole was received from Lee Pharma, Hyderabad, and test samples APTT and APMT were synthesized in Pharmaceutical Chemistry Laboratory, Abhilashi College of Pharmacy as mentioned earlier. Albendazole and test drugs (APTT and APMT) were prepared as $12.5 \mathrm{mg} / \mathrm{mL}, 25 \mathrm{mg} / \mathrm{mL}, 50 \mathrm{mg} / \mathrm{mL}$, $100 \mathrm{mg} / \mathrm{mL}$, and $200 \mathrm{mg} / \mathrm{mL}$ concentrations using water, DMSO, and ethanol as solvents, respectively. 
2.3. Evaluation of Anthelmintic Activity with Housefly Worms. In each of the 10 Petri dishes containing $20 \mathrm{~mL}$ of the prepared, solidified, and sterilized housefly medium, a well having $1 \mathrm{~cm}$ diameter was made with the help of a borer at the centre. The freshly collected matured female houseflies were placed in each of the Petri dishes and covered. After 24 hours, eggs hatched out from the worms, which were white in color, and died houseflies were removed. The Petri dishes were cultured further for a period of 72 hours, resulting in the formation of worms with an average count of 32 worms in each Petri dish. From these only 25 worms from each Petri dish were taken for experiments and the remaining worms were removed from all Petri dishes.

The cultured Petri dishes were named for standard drug (SD) and test drugs (TD1 and TD2) with control. The concentrations of the drugs were noted on the respective Petri dishes. Drug solution $(0.2 \mathrm{~mL})$ was added to each and every well in each Petri dish, and the time was noted for standard and test drugs with control. Albendazole solution was used as reference standard drug and distilled water as control. All the Petri dishes were incubated at $37^{\circ} \mathrm{C}$. The worms were observed for motility. This was done after tapping the edges of the Petri dishes and allowing the worms to move freely towards the well, the worms that were alive would be seen moving. After paralysis, the arrest in the movement of the worms was clearly observed, while applying little pressure with tapped pen edges. The unparalysed motile worms were trapped towards the well, and the incubation process was carried out again. In the untreated control Petri dishes worms were viable for at least 10 days. The number, weight, age of worms, motility, paralytic activity, and death time were noted.

2.4. Collection of Earthworms. Earthworms (Pheretima posthuma) were collected from the swampy water along the Muthukur road, near Jagan's College of Pharmacy, Nellore, and Andhra Pradesh, India. The average size of worms was $5-8 \mathrm{~cm}$. Earthworms were identified and authenticated by Dr. Humanan Reddy, Professor of Entomology, Department of Zoology, Vikrama Simhapuri University, Nellore. The anthelmintic activity was carried out as per the method described elsewhere [9]. The assay was performed in vitro using adult earthworms owing to their anatomical and physiological resemblance with the intestinal round worms, parasites of human beings for preliminary evaluation of anthelmintic activity. A concentration of standard drug (albendazole) and synthetic test drugs (APMT and APTT) was prepared as described earlier.

2.5. Evaluation of Anthelmintic Activity Using Earthworms. Earthworms, each of average length of $6 \mathrm{~cm}$, were placed in Petri dishes containing $2 \mathrm{~mL}$ of various drug concentrations, $12.5 \mathrm{mg} / \mathrm{mL}, 25 \mathrm{mg} / \mathrm{mL}, 50 \mathrm{mg} / \mathrm{mL}, 100 \mathrm{mg} / \mathrm{mL}$, and $200 \mathrm{mg} / \mathrm{mL}$, of solutions. Albendazole solution was used as reference standard drug and distilled water as control. The worms were observed for the motility after incubating at $37^{\circ} \mathrm{C}$. This was done after pouring the Petri dishes content in the wash basin and allowing the worms to move freely.
By tapping the end of each worm with the index finger and applying a bit of pressure, the worms that were alive showed motility and those dead were nonmotile. The motile worms were returned to the respective Petri dishes containing drug solutions, and the incubation process was carried out again. In the control, the worms were viable for at least twelve days, which is similar to the findings reported earlier [1012]. The time taken for paralysis, motility activity of any sort, and death time of worms were observed and recorded after ascertaining that the worms did not move neither when shaken vigorously nor when dipped in warm water $\left(50^{\circ} \mathrm{C}\right)$.

\section{Results}

3.1. Anthelmintic Activity in Housefly Worms. All housefly worms were cultured with equal age (72 hours), size ( $3 \mathrm{~mm}$ length and $0.5 \mathrm{~mm}$ thickness) and weight $(0.01 \mathrm{mg})$. These worms were motile and resemble parasitic pinworms in human intestines. The number of worms was in the range of 25 to 48 worms in each plate, out of which only 25 worms were taken for anthelmintic activity evaluation; the remaining worms were removed from plates. The drugs solution of $0.2 \mathrm{~mL}$ was added in each well of the housefly worm culture plates, and time was noted. The results of the anthelmintic activity of drugs, based on time of paralysis and time of death, are shown in Table 1.

The effect of the drug albendazole at concentration $25 \mathrm{mg} / \mathrm{mL}$ had less time of paralysis compared with test drugs APTT and APMT. The time taken for paralysis in drug concentration of $50 \mathrm{mg} / \mathrm{mL}$ was less ( $25 \mathrm{mins}, 43$ seconds) for APMT as compared to albendazole.

3.2. Anthelmintic Activity in Earthworms. Fifteen earthworms were collected and immediately transferred to Petri dishes containing water. Each worm was weighed; the weights are shown in Table 2. Petri dishes were named as batch 1, 2, 3, 4, and 5 with various concentrations of drugs with respect to albendazole, APTT, and APMT. The results of the anthelmintic activity of drugs, based on time of paralysis and time of death, were shown in Table 2.

In the present anthelmintic activity study, when the time of paralysis and time of death were compared between housefly worms and earthworms, the results showed that the time taken for paralysis and death is more for housefly worms than earthworms. In housefly worms, the time between paralysis and death was higher as compared to earthworms results.

3.3. Statistical Analysis. Worm counts were expressed as mean \pm SEM. The significance of difference between the means was determined by Student's $t$-test using a computer software package (SPSS for Windows Release 6.0) and considered as significant when $P<0.05$.

\section{Discussion}

The anthelmintic activities of albendazole and test (APTT and APMT) drugs in housefly worms and earthworms 


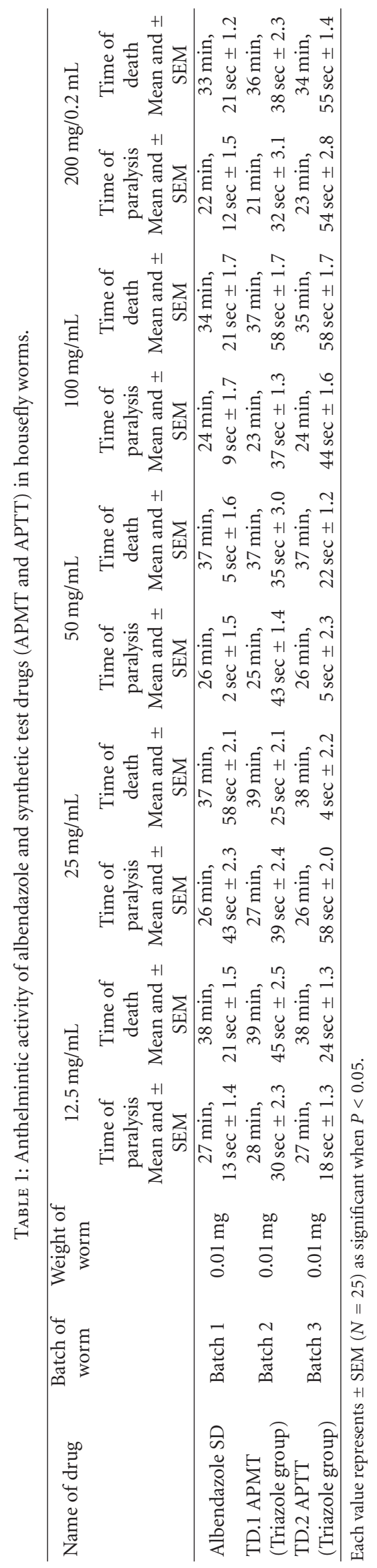




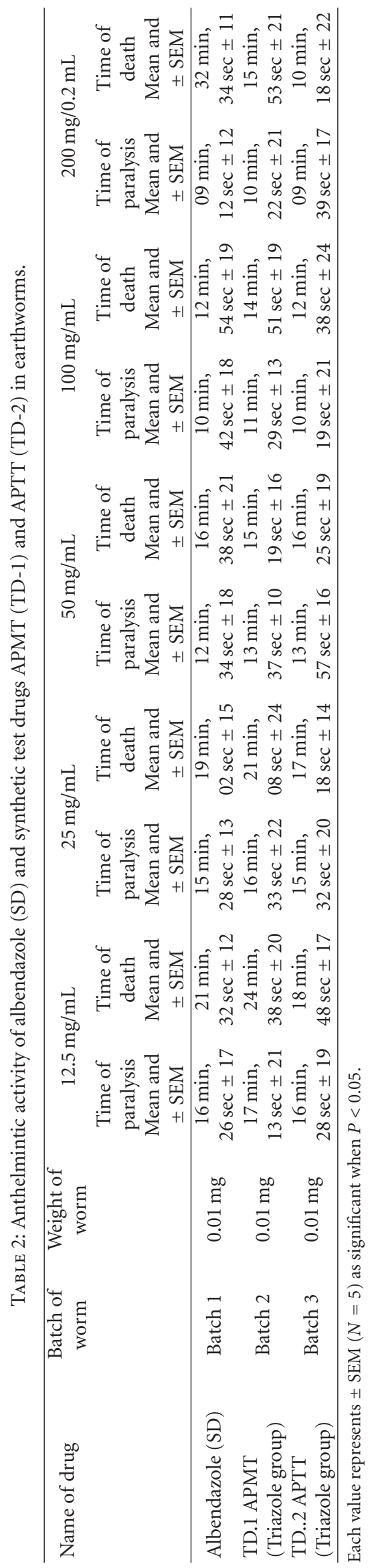


were performed in the laboratory conditions. The results of anthelmintic activities in housefly worms compared with earthworms showed that the housefly worms had taken more time for paralysis and more time for death. Several authors have reported that the drug affects only the viability of parasitic stages of helminthes [13-16] but it does not exhibit wormicidal activity in its native environment of worms, so the worms were not adjusted to the new laboratory environment. In order to establish the efficacy of an anthelmintic activity of any drug [17], the test animals should be allowed to adjust to a new environment $[18,19]$, therefore in the present study the housefly worms were treated in a similar manner to laboratory culture.

Even after paralysis the time taken for death was more in housefly worms even though size and weight of the worms were less as compared to earthworms. It was observed that the earthworms do not adapt easily to the laboratory conditions unlike the housefly worms.

Therefore, it can be concluded that housefly worms can be used successfully for the anthelmintic activity study as it is easy, prominent, an adaptable to laboratory conditions, and reproducible method in all aspects such as equal age, size and weight of the worms. In addition, the new method developed for evaluation of the anthelmintic activity of drugs in housefly worms is easy, prominent, eco-friendly, and reproducible. Also the worms of uniform size, age, and weight were cultured in adaptable conditions as shown in Section 3. This experiment was to provide natural environment to the worms and was used for evaluating the effect different doses of the drugs on the viability of the preparasitic stages of the helminthics. In conclusion the adaptable factors known to us have influence on the anthelmintic activity of the drugs. Moreover, there was a need for an alternative method apart from the conventional method to justify anthelmintic studies in laboratory investigations. Further studies have to follow up the improved new methodology in evaluating the anthelmintic activity for any drug with potential role in worm infections.

\section{Conflict of Interests}

The authors declare no conflict of interests.

\section{References}

[1] K. D. Chatterjee, Patasitology, Protozoology and Helminthology, Guha Ray, Sree Saraswaty Press, Calcutta, India, 1967.

[2] N. Mathew, S. Misra-Bhattacharya, V. Perumal, and K. Muthuswamy, "Antifilarial lead molecules isolated from Trachyspermum ammi," Molecules, vol. 13, no. 9, pp. 2156-2168, 2008.

[3] D. A. P. Bundy, "Immunoepidemiology of intestinal helminthic infections 1. The global burden of intestinal nematode disease," Transactions of the Royal Society of Tropical Medicine and Hygiene, vol. 88, no. 3, pp. 259-261, 1994.

[4] R. J. Martin, "Modes of action of anthelmintic drugs," Veterinary Journal, vol. 154, no. 1, pp. 11-34, 1997.

[5] P. J. Waller, “Anthelmintic resistance," Veterinary Parasitology, vol. 72, no. 3-4, pp. 391-412, 1997.
[6] S. Kosalge and R. A. Fursule, "Investigation of in vitro anthelmintic activity of thespesia lampas (Cav.)," Asian Journal of Pharmaceutical and Clinical Research, vol. 2, no. 2, pp. 69-71, 2009.

[7] R. D. Vidyarthi, A Text Book of Zoology, S. Chand \& Company, New Delhi, India, 1967.

[8] R. Mali and R. Wadekar, "In vitro anthelmintic activity of Baliospermum montanum muell. arg roots," Indian Journal of Pharmaceutical Sciences, vol. 70, no. 1, pp. 131-133, 2008.

[9] E. O. Ajaiyeoba, P. A. Onocha, and O. T. Olarenwaju, "In vitro anthelmintic properties of Buchholzia coriaceae and Gynandropsis gynandra extracts," Pharmaceutical Biology, vol. 39, no. 3, pp. 217-220, 2001.

[10] K. Mamoudou Kande, S. Philipov, and H. Dutschewska, "Alkaloids of Xylopia aethiopica," Fitoterapia, vol. 65, no. 1, pp. 89-90, 1994.

[11] L. M. Pessoa, S. M. Morais, C. M. L. Bevilaqua, and J. H. S. Luciano, "Anthelmintic activity of essential oil of Ocimum gratissimum Linn. and eugenol against Haemonchus contortus," Veterinary Parasitology, vol. 109, no. 1-2, pp. 59-63, 2002.

[12] T. Innocent and O. Deogracious, "The anthelmintic activity of selected indigenous medicinal plants used by The Banyankole of Western Uganda," Journal of Animal and Veterinary Advances, vol. 5, pp. 712-717, 2006.

[13] R. L. Coop and P. H. Holmes, "Nutrition and parasite interaction," International Journal for Parasitology, vol. 26, no. 8-9, pp. 951-962, 1996.

[14] M. F. J. Van Houtert and A. R. Sykes, "Implications of nutrition for the ability of ruminants to withstand gastrointestinal nematode infections," International Journal for Parasitology, vol. 26, no. 11, pp. 1151-1167, 1996.

[15] J. Donaldson, M. F. J. V. houtert, and A. R. Sykes, "The effect of protein supply on the peripaturient parasite status of the mature ewe," in Proceedings of the New Zealand Society of Animal Production, vol. 57, pp. 186-189, 1997.

[16] A. A. Gbolade and A. A. Adeyemi, "Investigation of in vitro anthelmintic activities of Pycnanthus angolensis and Sphenocentrum jollyanum," Fitoterapia, vol. 79, no. 3, pp. 220222, 2008.

[17] J. L. Duncan, J. H. Arundel, J. H. Drudge, A. Malczewski, and J. O. D. Slocombe, "World Association for the Advancement of Veterinary Parasitology (W.A.A.V.P.) guidelines for evaluating the efficacy of equine anthelmintics," Veterinary Parasitology, vol. 30, no. 1, pp. 57-72, 1988.

[18] H. M. Gordon, "Studies on anthelmintics for sheep," Australian Veterinary Journal, vol. 33, no. 1, pp. 1-7, 1957.

[19] S. Athanasiadou, I. Kyriazakis, F. Jackson, and R. L. Coop, "Direct anthelmintic effects of condensed tannins towards different gastrointestinal nematodes of sheep: in vitro and in vivo studies," Veterinary Parasitology, vol. 99, no. 3, pp. 205219, 2001. 

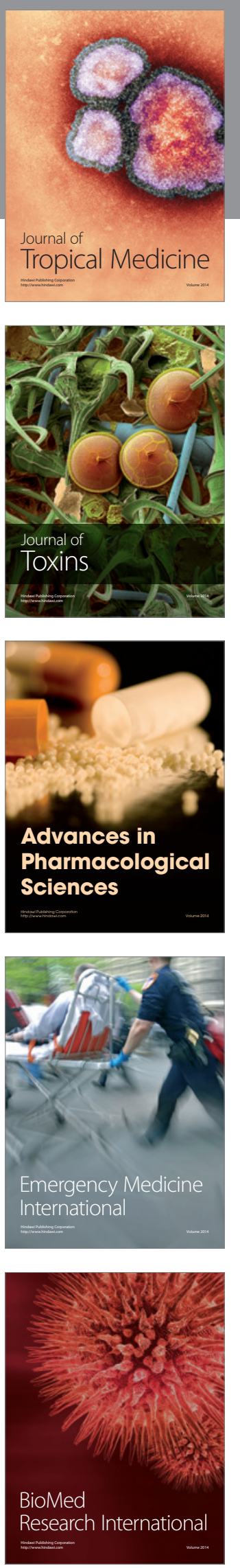
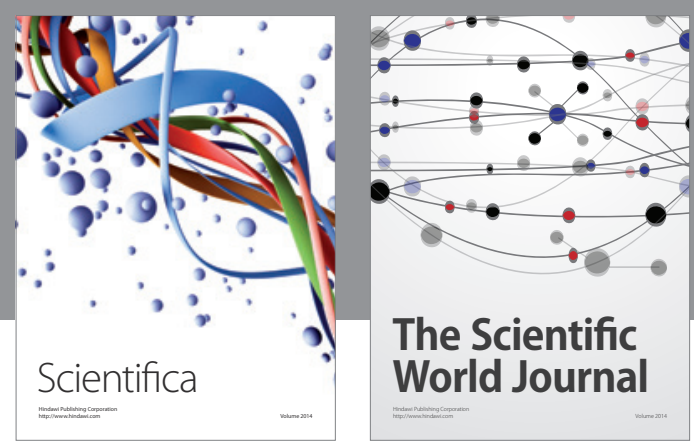

The Scientific World Journal
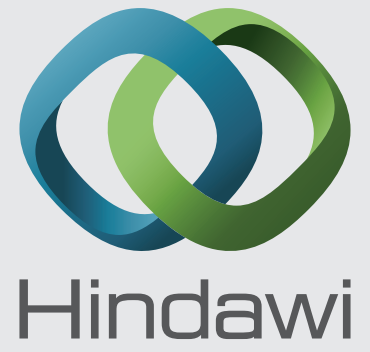

Submit your manuscripts at

http://www.hindawi.com
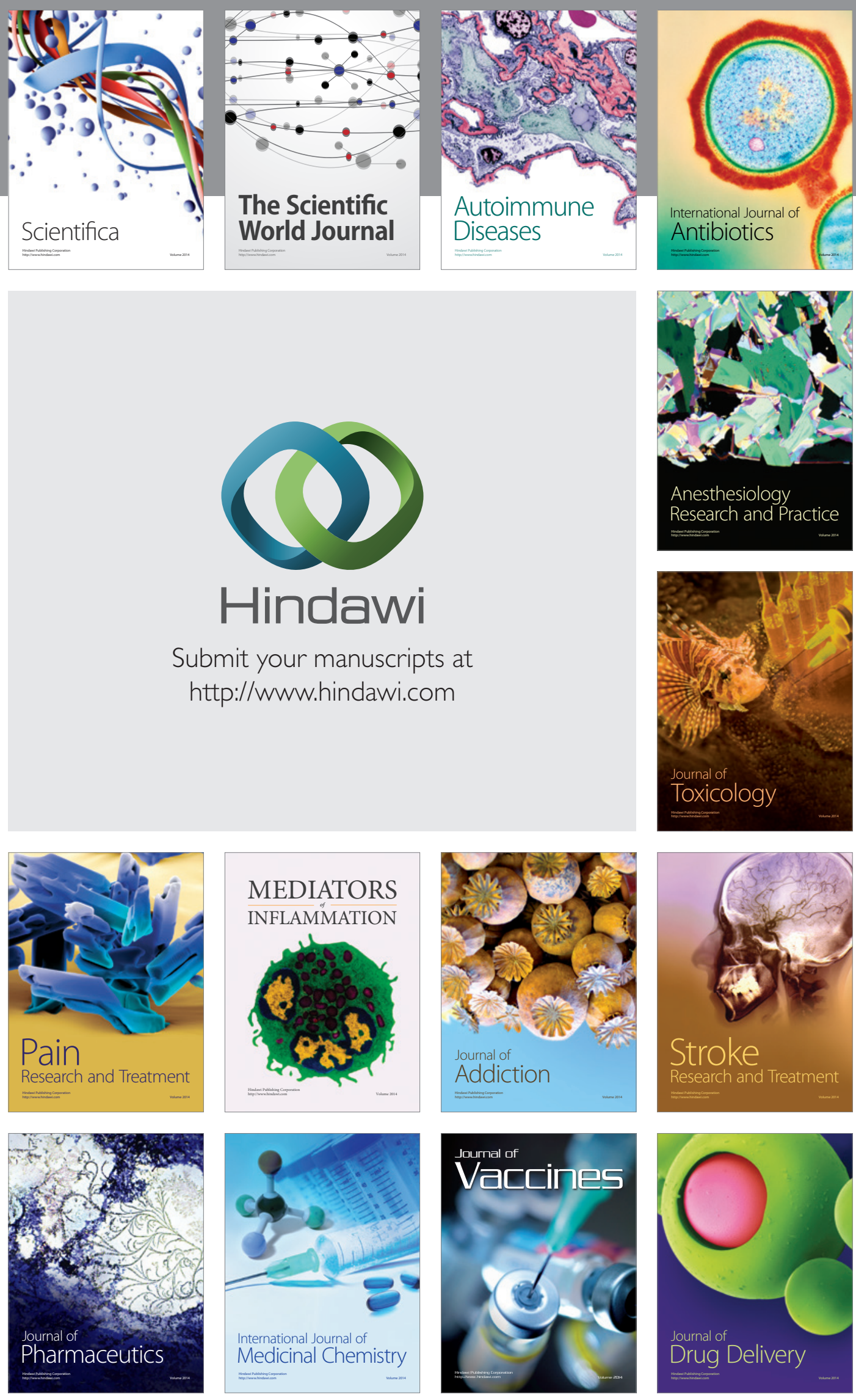